\title{
Synchronous and Rhythmic Vocalizations and Correlated Underwater Behavior of Free-ranging Atlantic Spotted Dolphins (Stenella frontalis) and Bottlenose Dolphins (Tursiops truncatus) in the Bahamas
}

\author{
Denise L. Herzing ${ }^{1,2 *}$ \\ ${ }^{1}$ Wild Dolphin Project \\ ${ }^{2}$ Florida Atlantic University \\ *Corresponding author (Email: wdpdenise@wilddolphinproject.org) \\ Citation - Herzing, D. L. (2015). Synchronous and rhythmic vocalizations and correlated underwater behavior of \\ free-ranging Atlantic spotted dolphins (Stenella frontalis) and bottlenose dolphins (Tursiops truncatus) in the \\ Bahamas. Animal Behavior and Cognition, 2(1), 14-29. doi: 10.12966/abc.02.02.2015
}

\begin{abstract}
Since 1985 a resident community of Atlantic spotted dolphins (Stenella frontalis), and bottlenose dolphins (Tursiops truncatus), have been studied underwater in the Bahamas. Over 200 individuals of both species have been identified and observed over the years. Basic correlations with sound patterns and behavior such as whistles during contact/reunions and squawks during aggression have been reported. This paper describes a small subset of their vocal repertoire that involves synchronous/rhythmic sound production. Dolphin behavior was recorded underwater using underwater video cameras with hydrophone input. Vocalizations were correlated with basic underwater behavioral activity and analyzed using Raven 1.3. Spotted dolphins were observed using two types of synchronized vocalizations including synchronized squawks (burst pulsed vocalizations) and screams(overlapping FM whistles) during intraspecific and interspecific aggression. Bottlenose dolphins used three types of synchronized vocalizations; whistles/buzz bouts, bray/buzz bouts, and buzz bouts during intraspecific aggression. Body postures were synchronous with physical movements and often mirrored the rhythm of the vocalizations. The intervals between highly synchronized vocalizations had small variance and created a rhythmic quality and cadence to the acoustic sequences. Three types of vocalizations had similar ratios of sound duration to the spacing between sounds (Screams, whistle/buzz bouts, and bray/buzz bouts). Temporal aspects of sequences of sound and postures may be important aspects of individual and group coordination and behavior in delphinids.
\end{abstract}

Keywords - Synchrony, Rhythm, Vocalizations, Dolphins, Interspecific, Intraspecific, Behavior

Synchrony, both visual and acoustic, occurs in a variety of taxa in the animal kingdom. Visual synchrony occurs in terrestrial animals and includes fireflies that synchronize their bioluminescent flashing in the tropical night (Buck, 1988) and clusters of male fiddler crabs that wave their claws in synchrony to attract females for mating (Backwell, Jennions, \& Passmore, 1998). Acoustic synchrony has also been described for insects that synchronize their chirps in multi-male chorusing (Greenfield \& Shaw, 1983; Otte, 1977), in chorusing frogs (Klump \& Gerhardt, 1992; Wells, 1977), in young wolves (Coscia, Phillips, \& Fentress, 1991) and in other taxa (Greenfield \& Roizen, 1993; Nityananda \& Balakrishnan, 2008).

Acoustic synchrony has been described as a rhythmic repetition of signals in conformity with a regular beat or pulse (Greenfield, 1994). Pulse-born acoustic synchrony in bonobo chimpanzees is described by de Waal (1988) as staccato hooting that is almost perfectly synchronized in a steady rhythm 
of about two calls per second. Choruses and duets are also observed in a variety of taxa. The difficulty of consistently identifying subjects that utter each vocalization within a group makes analysis of acoustic synchrony challenging. Duets usually involve two individuals whose vocalizations co-occur, most often in association with social monogamy and territoriality (e.g., primates - Haimoff, 1986; Robinson, 1981). Choruses involve more than two individuals producing a chorus during which there may be some temporally distinct vocal units, and some overlapping vocal units (Baker-Medard, Baker, \& Logue, 2013). Chorusing by groups can be alternating or synchronous and does not necessarily involve overlapping vocalizations but instead may have a sequential nature with only slight temporal overlaps of sounds.

When synchrony (vocal and physical) is involved in simultaneous calling events, synchrony has been thought to have evolutionary advantages for multi-male groups during various behavior activities (Greenfield, 1994). Rhythmic acoustic signals are a component of synchronous calling, and when present are defined by equal spacing between sounds during acoustic events (e.g., Maier, 1982; Zelick \& Narins, 1983), but rhythm may not be present in all behaviors. Hershey and Movellan (1999) have specifically described the importance of localizing acoustic signals using correlated visual signals. Synchronized vocal behavior also appears to involve vocal learning and convergence for a few social mammal species including primates and cetaceans (Boesch, 1991; Janik \& Slater, 1997, 2000; Marler \& Mundinger, 1971; Nottebohm, 1976).

Synchronous surfacing, breathing, and diving has been reported for small delphinids and odontocetes, including Indian Ocean bottlenose dolphins Tursiops aduncus (Connor, Smolker, \& Bejder, 2006; Mann \& Smuts, 1999; Sakai, Morisaka, Kogi, Hishii, \& Kahshima, 2009), during herding behavior of females (Connor \& Smolker, 1996; Connor, Smolker, \& Richards, 1992), in bottlenose dolphin breathing Tursiops truncatus (Hastie, Wilson, Tufft, \& Thompson, 2003; Perelberg \& Schuster, 2008), during the coordination of spinner dolphin behavior Stenella longirostris (Brownlee \& Norris, 1994), in male pantropical spotted dolphin, Stenella attenuata, behavior observed in tuna-nets (Pryor \& KangShallenberger, 1991), in killer whale behavior Orcinus orca (Heimlich-Boran, 1988), in pilot whale breathing Globicephala sp. (Senigaglia \& Whitehead, 2012), and in sperm whale diving Physeter catadon (Whitehead, 1996).

Vocal chorusing has been reported in bottlenose dolphins (Janik, Simard, Sayigh, Mann, \& Frankel, 2011) and rhythmic braying has been recorded during various social behavior for bottlenose dolphins in Portugal (dos Santos, Ferreira, \& Harzen, 1995). Synchronous screams and squawks have been correlated with underwater behavior in Atlantic spotted dolphins, Stenella frontalis, and bottlenose dolphins during intra and interspecific aggression (Herzing, 1996; Herzing \& Johnson, 1997).

Although many types of these synchronized vocalizations have been recorded for cetaceans, the correlated underwater behavior and function of these vocalizations is often unknown due to the lack of underwater observations. This paper describes five synchronized vocalizations types (Figure 3 A-E) used rhythmically and correlated with underwater behavior for two species of delphinids. 1) Squawks are a type of discrete non-tonal burst-pulsed sound, usually less than $1.5 \mathrm{sec}$ long with varying repetition rates between 200 - 1200 clicks per second (Herzing, 1996). Squawks are described for various dolphins and toothed whales (Herzing, 1996, 2000; Overstrom, 1983; Sjare \& Smith, 1986) and are typically used in close proximity aggressive communication. Synchronized squawks are highly coordinated, temporarily discrete, burst-pulsed vocalizations that have been described for Atlantic spotted dolphins in the context of male aggression between Atlantic spotted dolphins and bottlenose dolphins in the Bahamas (Herzing, 1996); 2) Screams are a tonal sound and consist of 5 or 6 overlapping FM whistles made by multiple animals simultaneously. Screams have been described for Atlantic spotted dolphins by Herzing (1996) during highly escalated agonistic/aggressive interspecies dolphin aggression, and recently described for bottlenose dolphins but labeled as chorusing whistles (Janik et al., 2011); 3) Frequency-modulated (FM) whistles are tonal sounds and signature whistles are especially well-studied (Caldwell, Caldwell, \& Tyack, 1990; Tyack, 1993; McCowan \& Reiss, 1995). Whistles are used for contact and reunion events and as long-distance signals; 4) Brays are a two-part burst-pulsed sound, typically < $0.5 \mathrm{~s}$ long per part, and were first described during social behavior for bottlenose dolphins in Portugal by dos Santos, Caporin, Moreira, Ferreira, \& Coelho, 1990, and later in detail by dos Santos et al., 1995, and later 
described for bottlenose dolphins in Scotland during surface-defined foraging measures (Janik, 2000); 5) Buzzes are click trains that last from $>1 \mathrm{~s}$ up to minutes and have various repetition rates between $200-$ 2000 clicks per sec and are used for both foraging and social purposes including discipline, courtship, and aggression (Herzing 1996, 2000, 2004).

The objective of this paper is to describe the vocal features and rhythmic components of these five types of vocalizations when used in synchronous and rhythmic bouts and their correlated underwater behavior. Identifying the vocalizer in most studies is difficult. For these observations synchronous vocalizations were matched with synchronous physical behavior to identify the potential vocalizers. Two types, Synchronized Squawks and Synchronized Screams, are described for Atlantic spotted dolphins. Three types, Synchronized Whistle/Buzz Bouts, Synchronized Bray/Buzz Bouts, and Synchronized Buzz. Bouts, are described for bottlenose dolphins.

\section{Method}

\section{Field Site and General Data Collection}

In the Bahamas, a resident group of Atlantic spotted dolphins have been behaviorally observed underwater on Little Bahama Bank (LBB) since 1985. Life history (Herzing, 1997) and correlations with sound and behavior (Herzing, 1996, 2000, 2004), ultrasonic vocalizations (Lammers, Au, \& Herzing, 2003), social structure (Elliser \& Herzing, 2012, 2014), and genetics (Green, Herzing, \& Baldwin, 2011) have been described. In the Bahamas a complicated relationship also exists between Atlantic spotted dolphins (Stenella frontalis) and bottlenose dolphins (Tursiops truncatus). Previous observations have shown a variety of regular affiliative and aggressive behaviors (Herzing \& Johnson, 1997). Long-term interactions between these sympatric Atlantic spotted dolphins and bottlenose dolphins in the Bahamas have been observed consistently every summer since 1985 . These two species spend $15 \%$ of their time engaged in interspecies activities including foraging, traveling, play, alloparental care, aggressive activity and interspecific alliances (Herzing \& Johnson, 1997). The importance of synchronous male spotted dolphin behavior during fights with bottlenose dolphins has also been described (Cusick \& Herzing, 2014).

Since 1985 Atlantic spotted dolphins and bottlenose dolphins have been observed every summer for approximately 100 days, May through September, on Little Bahama Bank (LBB). These two species are resident and sympatric and have a clear physical size difference: an adult bottlenose dolphin is approximately $1 \mathrm{~m}$ larger than an adult spotted dolphin. This is an area of shallow water, ranging approximately 6 to $16 \mathrm{~m}$ in depth, $480 \mathrm{~km}^{2}$ in size. Underwater visibility averages $30 \mathrm{~m}$. Observations were conducted using a 20 -m motor-powered catamaran.

When dolphins were encountered researchers entered the water to obtain underwater video and simultaneous sound using various cameras (e.g., Sony TRV PC110, Sony XR550) with attached hydrophones (e.g., Labcore up to $20 \mathrm{kHz},-192 \mathrm{~dB}$ re $1 u \mathrm{~Pa}$ ). Sampling included ad libitum, focal, and behavioral events (Altmann, 1974). All dolphins were identified using standard photo identification techniques using underwater cameras, and determination of sex was accomplished by underwater visual observation of the genital area. Age classes for spotted dolphin were classified using Herzing (1997) modified after $S$. attenuata (Perrin, 1970) and the life history, reproductive activity, association patterns, and underwater sound and behavior of these resident dolphins have been well documented for over 29 years, spanning three generations. Bottlenose dolphins were classified as adults, juveniles, and calves.

Other data recorded include date, time, location, associations, environmental information, and general behavioral activity. Video information was logged and reviewed every evening on board the research vessel and included detailed notes and scoring of underwater behaviors and vocalizations. This long-term data set of audio and visual information has been archived since 1985 and is accessible for detailed analysis based on individuals (220 spotted dolphins, 200 bottlenose dolphins), age classes, and general behavior categories (foraging, aggression, courtship, discipline, traveling, playing). Although spotted dolphins were the main focus of this long-term project and most frequently recorded, we also 
occasionally observed the underwater behavior of bottlenose dolphins.

\section{Sound and Behavior Recordings - Atlantic Spotted Dolphins}

Atlantic spotted dolphin video samples were selected for 5 adult interspecific encounters, 2 adult intraspecific aggressive encounters, and 5 juvenile intraspecific aggressive encounters when synchronous vocalizations were present (Table 1). Synchronized squawks were extracted from the underwater video when coalitions of male spotted dolphins were tightly grouped together and chasing either a bottlenose dolphin or another male spotted coalition. Screams were extracted in segments when male spotted coalitions were huddled tightly together with open mouths and showed general agitation after an intraspecific fight. A total of 24 screams and their 22 ISIs (Inter-signal intervals), 116 adults synchronized squawks and their 89 ISI's, and 63 juvenile synchronized squawks and their 58 ISI's were measured. Because of the extreme rhythmic nature of one sequence (08209202) the vocal sequence was divided into presynch, maximum synch, and post synch, to measure the most synchronized squawks within the sequence. All spectrograms were generated and measured using Raven Pro software.

Spotted dolphins used synchronized screams during intraspecific fights, and synchronized squawks during both intra and interspecific aggressive contexts. Only male spotted dolphins were observed to coordinate their behavior and apparent vocalizations in these settings (Figure 1A). During these interspecific fights bottlenose males were sometimes observed synchronizing their leaps out of the water and reentry into the water, with no apparent vocal coordination by the bottlenose dolphins.

Table 1

Description of Dolphin Encounters that Contained Synchronous or Rhythmic Vocalizations. (SP = Spotted dolphin, $B N=$ Bottlenose dolphin, $A D=$ adults, $J U V=$ Juveniles)

\begin{tabular}{|c|c|c|c|}
\hline Month/day/year/Encounter \# & Time-video log & Vocalization Type & Species \& Age \\
\hline 07040001 & 06:00 & Synchronized Squawks & SP/BN AD \\
\hline 08310202 & $33: 00$ & Synchronized Squawks & SP/BN AD \\
\hline 07040301 & 20:04/21:30 & Synchronized Squawks & SP/BN AD \\
\hline 07310502 & $44: 55$ & Synchronized Squawks & SP/BN AD \\
\hline 08209202 & $52: 00$ & Synchronized Squawks & $\mathrm{SP} / \mathrm{BN} \mathrm{AD}$ \\
\hline 06090104 & $1: 23: 30$ & Synchronized Screams & SP AD \\
\hline 06100302 & $14: 00$ & Synchronized Screams & SP AD \\
\hline 08210104 & $9: 45$ & Synchronized Squawks & SP JUV \\
\hline 06180301 & $5: 37$ & Synchronized Squawks & SP JUV \\
\hline 07100401 & $28: 50$ & Synchronized Squawks & SP JUV \\
\hline 08210403 & $25: 30$ & Synchronized Squawks & SP JUV \\
\hline 08190101 & 29:00 & Synchronized Squawks & SP JUV \\
\hline 08230602 & 34:00/49:00 & $\begin{array}{c}\text { Synchronized Whistle/Buzz } \\
\text { Bray/Buzz, \& Buzz }\end{array}$ & $\mathrm{BN} \mathrm{AD}$ \\
\hline
\end{tabular}


A)

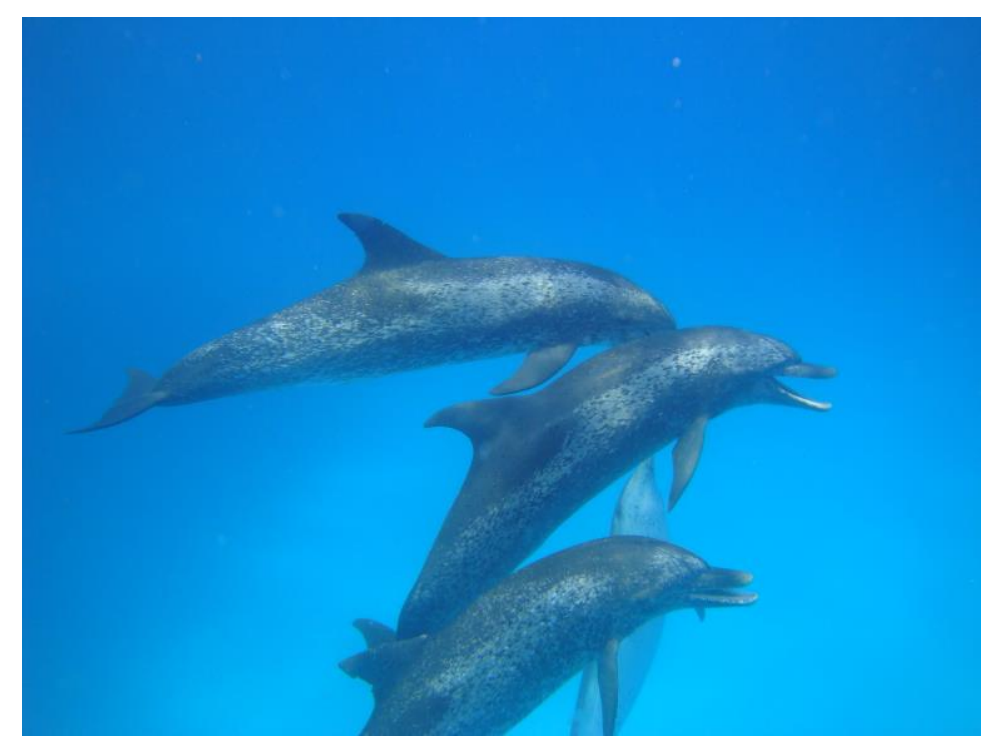

\section{C)}

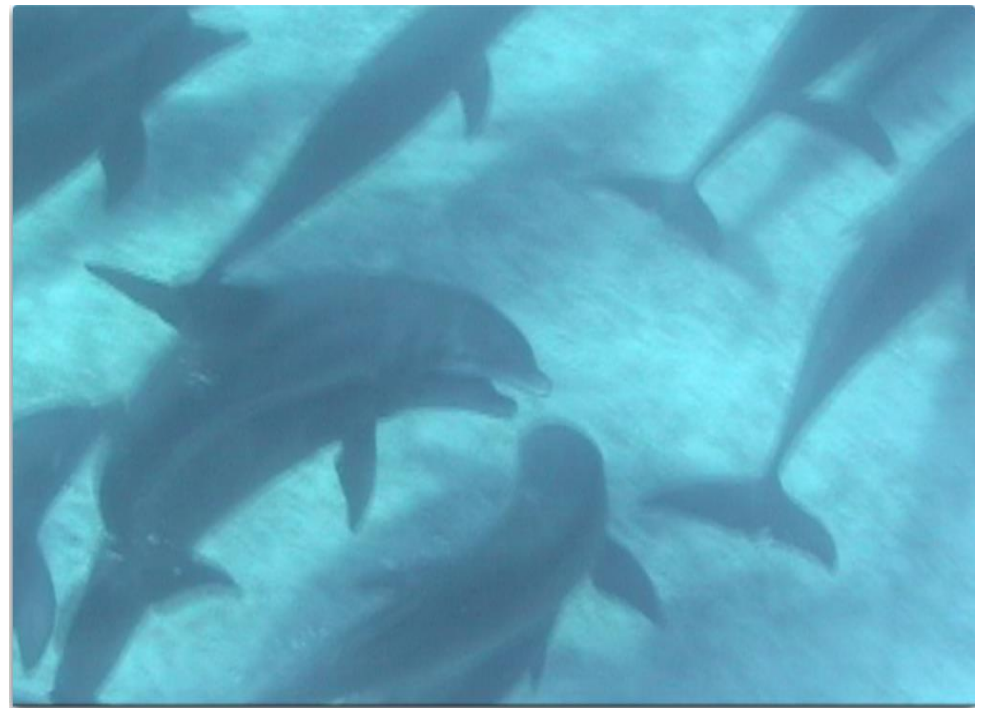

B)

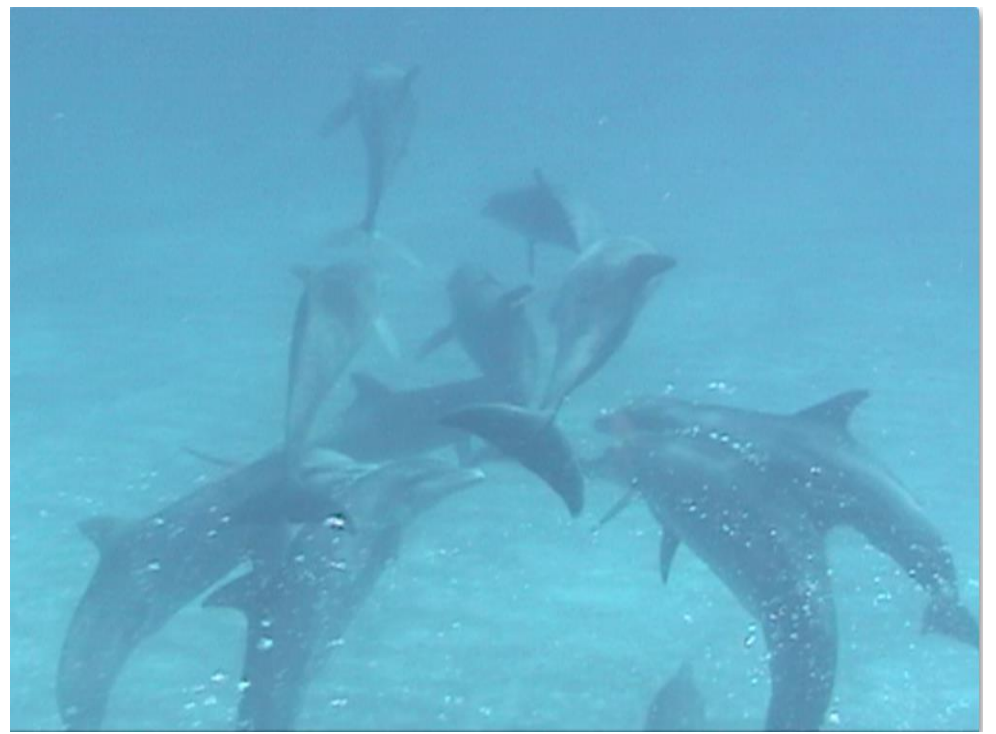

Figure 1. Behaviors observed during synchronized vocalizations. A) Male Atlantic spotted dolphins chase bottlenose during Synchronized Squawks and Synchronized Screams, B) Male Atlantic bottlenose dolphins dyads go head-to-head and expel bubbles, and C) Male Atlantic bottlenose dolphin dyads coordinate orientation during whistle/buzzes, bray/buzzes, and synchronized buzzes. 


\section{Sound and Behavior Recordings - Bottlenose Dolphins}

Bottlenose dolphin synchronized vocalizations were extracted from one unique intraspecific aggressive encounter at 1525 on 23 August 2006, when a rare underwater observation of social behavior occurred for 117 min (Table 1). The behavior of 30 bottlenose dolphins was recorded on underwater video. This group contained 12 adult males, 7 adult females, 4 unsexed adults, 3 juvenile males, 1 juvenile female, 1 unsexed juvenile, 2 female calves. When dyads of dolphins began coordinating their head to head aggressive orientations synchronized vocal bouts, along with jaw claps and tail slaps, ensued. One part of this recorded observation involved a synchronized vocalization bout consisting of two types of vocalizations, a whistle and a buzz, followed by a silence (Whistle/buzz bout, $N=9$ ) that was repeated multiple times. A second type of synchronized vocalization bout also contained a combination of two types of vocalizations, a bray sequence followed by a buzz, followed by silence (Bray/buzz bout $N=$ 6 ) and repeated multiple times. A third type of synchronized vocalization bout contained a single buzz (Buzz Bout) followed by silence and repeated multiple times. All bouts had a rhythmic quality to them and if they contained two types of vocalizations were measured separately (e.g., whistle measured, buzz measured) as well as one bout unit (e.g., total duration of whistle/space/buzz measured). Inter-signal intervals (ISI) between sound types and between bouts were also measured. Bouts were also measured as one unit (e.g., containing the whistle and the buzz) as well as the bout's ISI (Figure 2). During all three types of vocal bouts the bottlenose group displayed coordinated physical behavior. Bubble trails were seen coming from the coordinated individuals during all three types of bouts (sometimes an indication of the vocalizer) and physical behavior was also tightly synchronized during all displays (Figure 1B \& 1C). It is unknown if one dolphin, or two dolphins or more, are producing these bouts of sounds. But during the observation of synchronous vocalizations two dyads of male bottlenose faced off with each other and were observed synchronizing their head movements both within their dyad and between dyads. Other behavior that occurred during this encounter, but not during the synchronized vocalizations, included 2 males that followed 1 mother/calf pair, and 2 other males with visible erections that pursued 1 small female bottlenose dolphin.

Samples of all five vocalization types (Figure 3A-E, Figure 4A \& 4B) were extracted from the underwater video and processed in Raven 1.3. Frequency, duration, and inter-signal intervals were measured and described for each sound type and correlated with general behavior categories (Table 2). These vocalizations were only observed in aggressive or courtship contexts. 


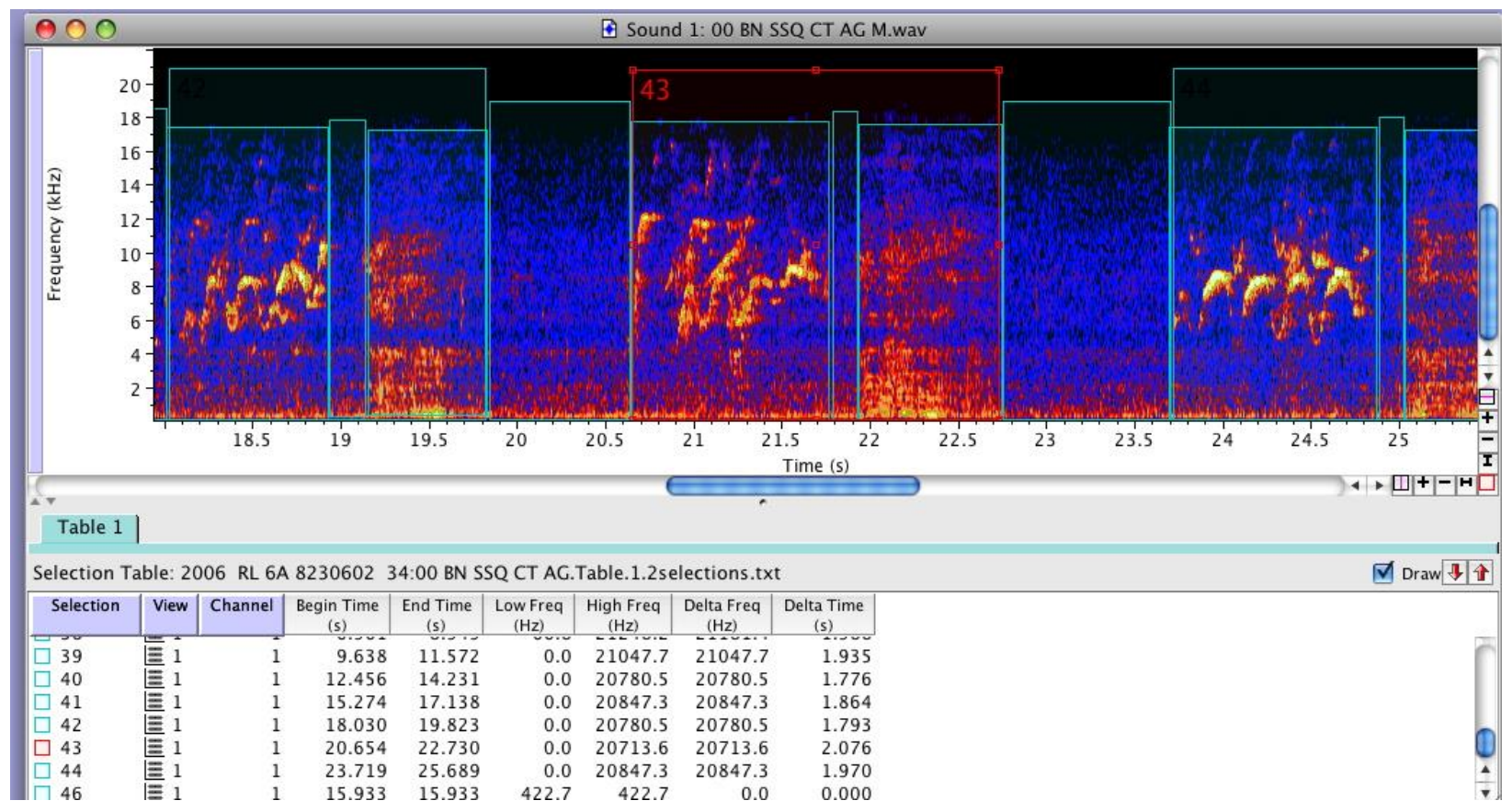

Figure 2. Example of a spectrogram and Raven measurements of a bottlenose dolphin whistle/buzz bout. Included are duration measurements of whistles, inter-signal interval (ISI) between the whistle and the buzz, and the buzz. Also measured is the duration of the combined whistle/ISI/buzz as a "bout" (43) and the ISI between "bouts" that are spaced between bouts.

A) Synchronized Squawks - Spotted Dolphins

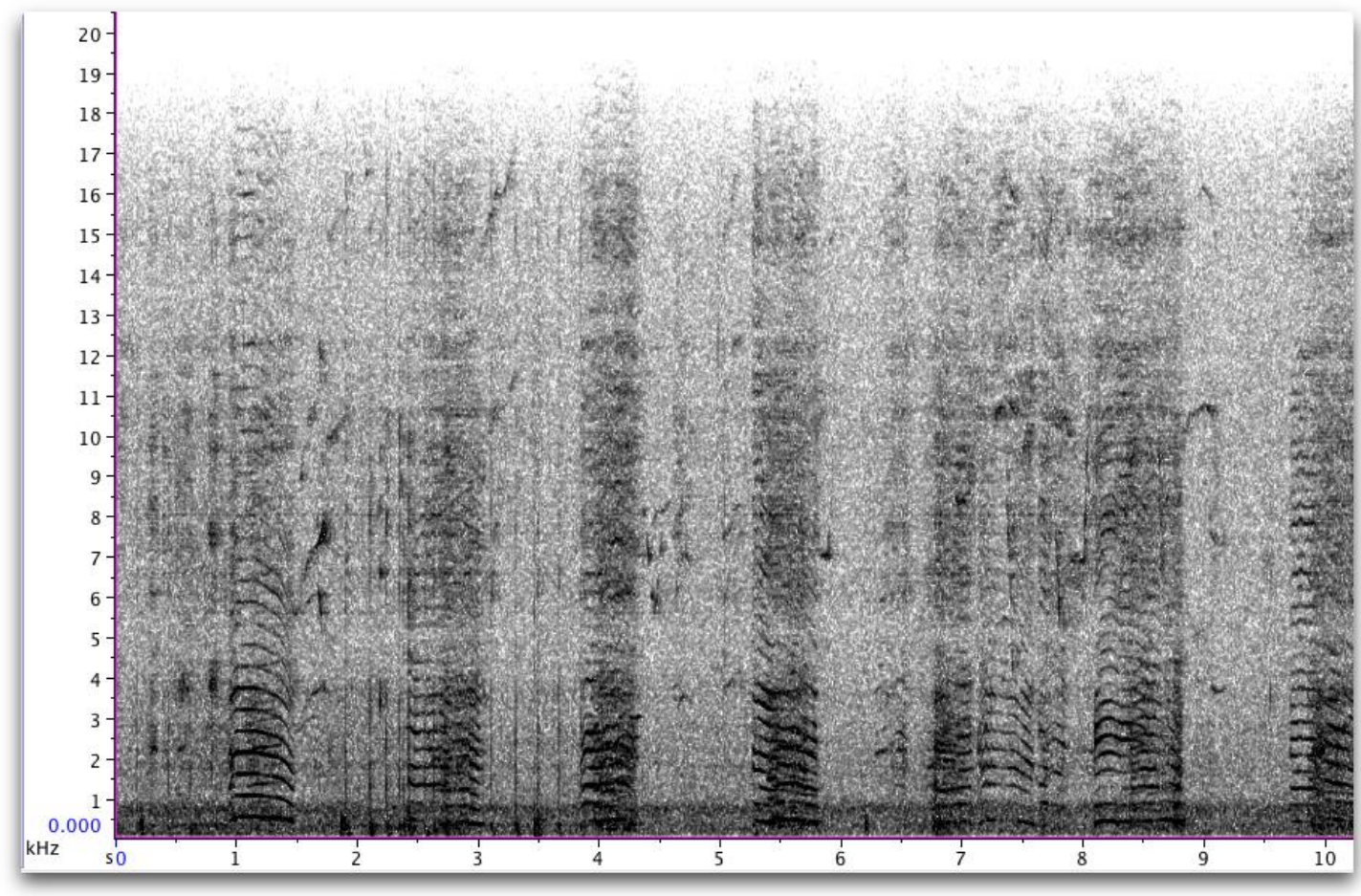


B) Synchronized Screams - Spotted Dolphins

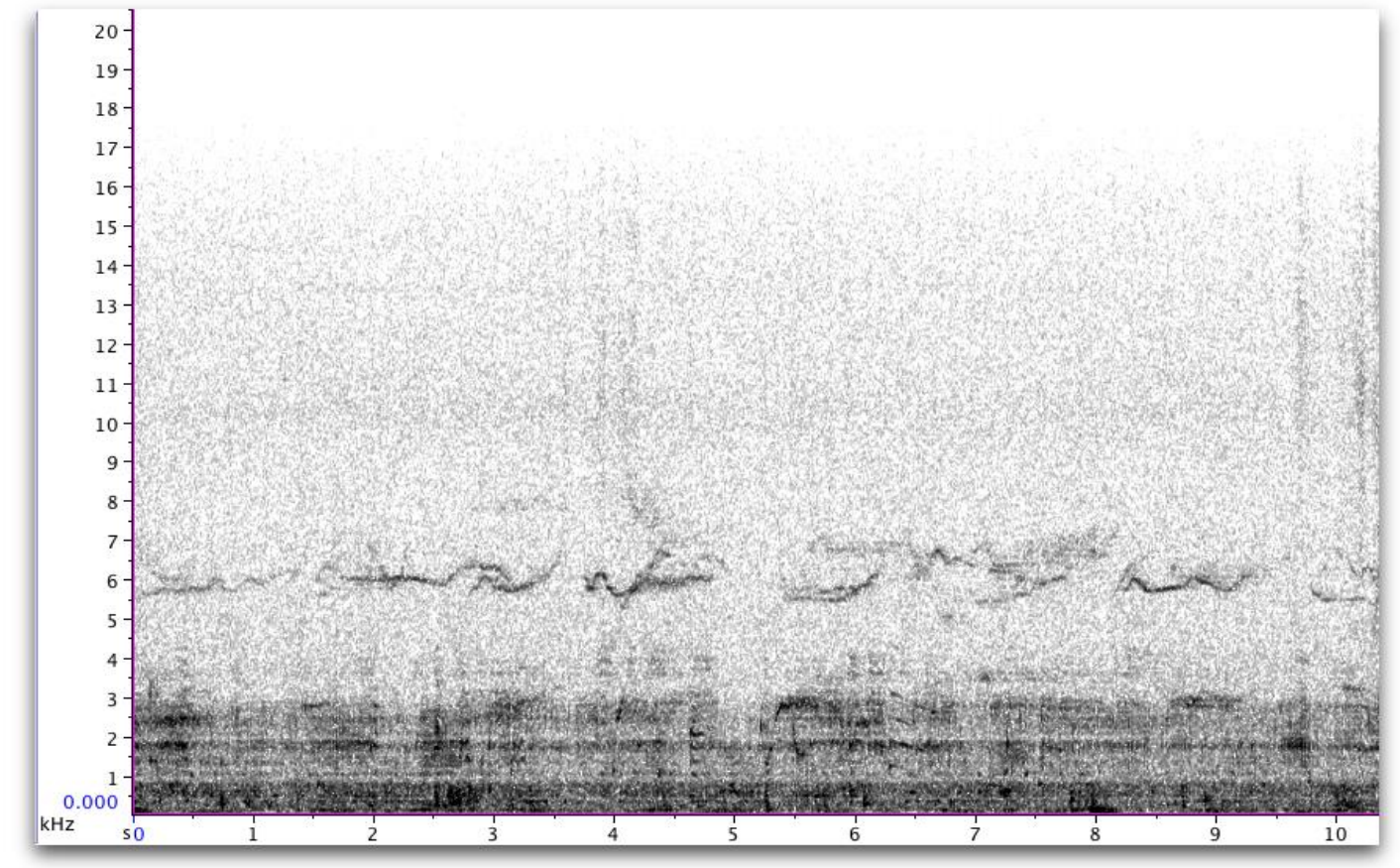

C) Frequency-modulated Whistles/Buzzes - Bottlenose Dolphins

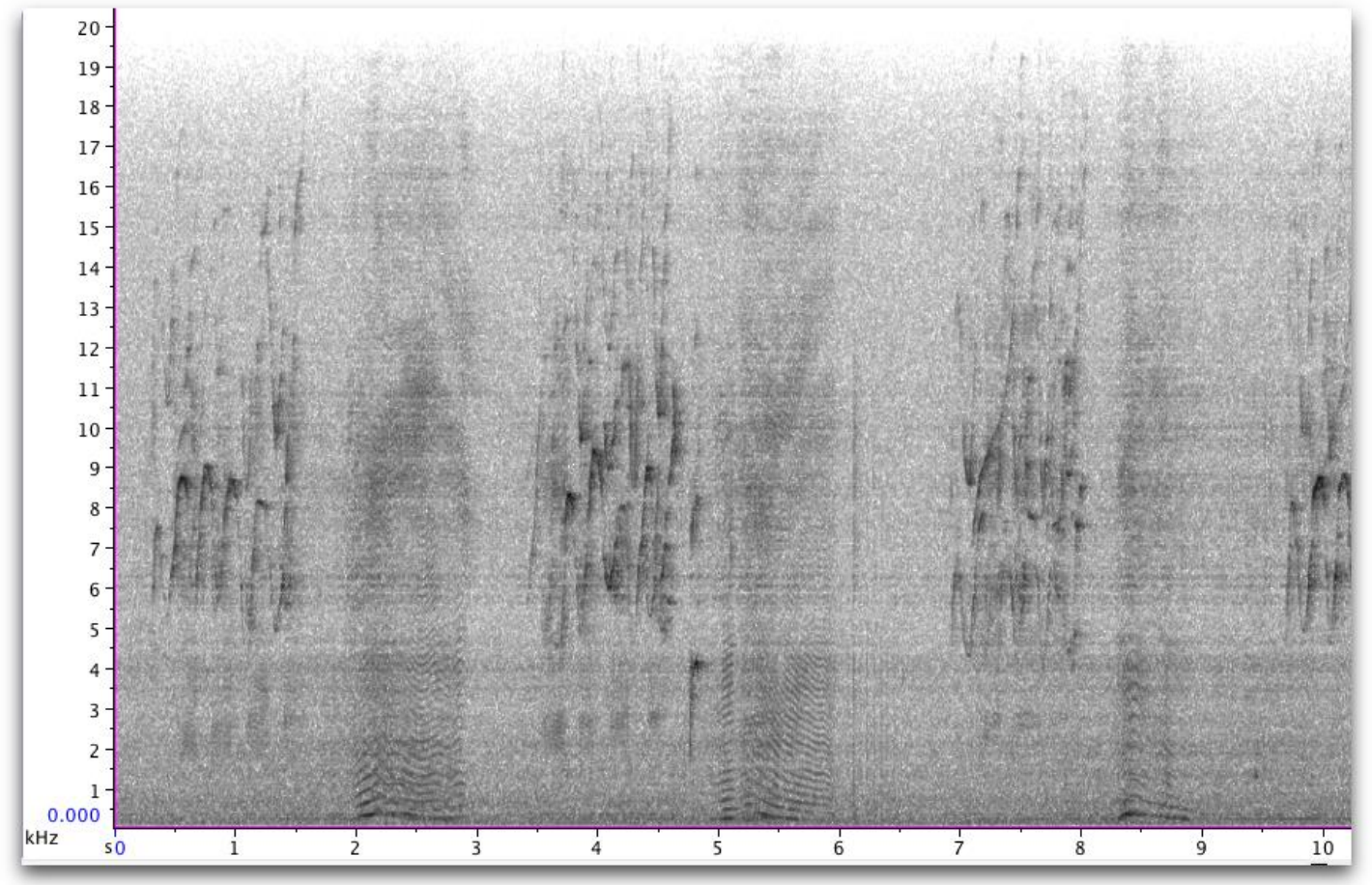




\section{D) Synchronized Brays/Buzz - Bottlenose Dolphins}

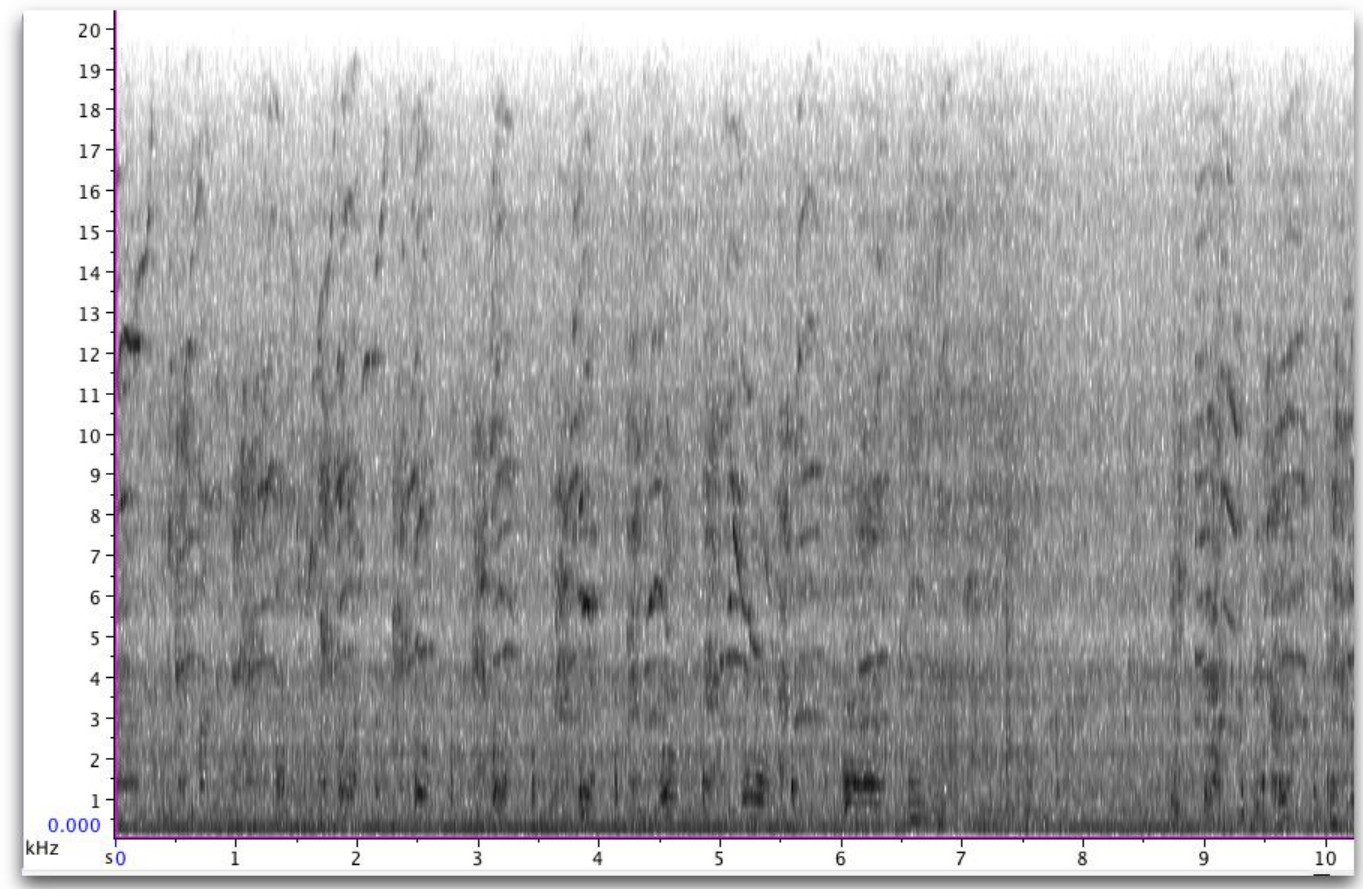

E) Synchronized Buzz - Bottlenose Dolphins

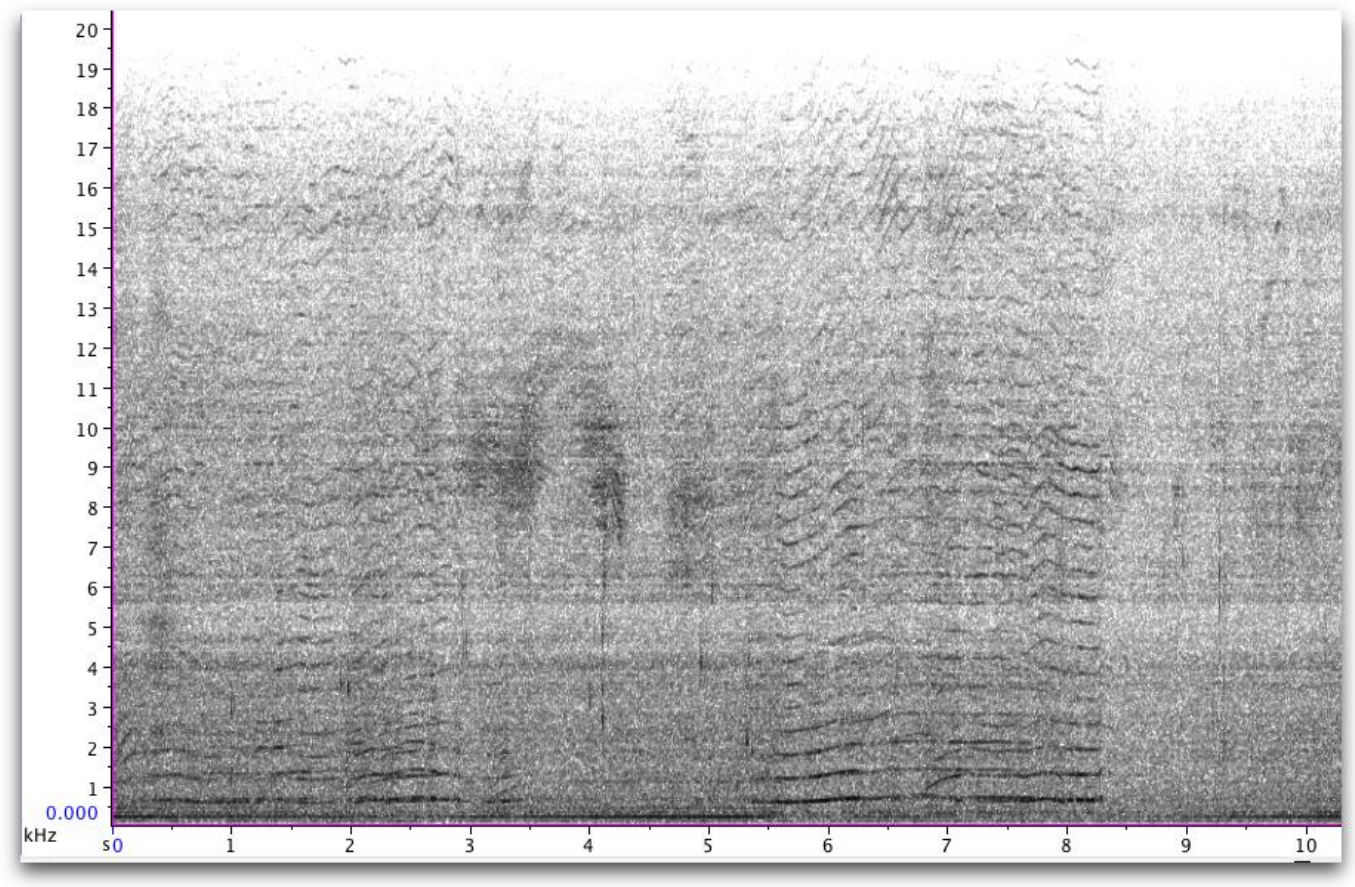

Figure 3. Spectrographic examples of five synchronized vocalizations types. A) Synchronized Squawks of spotted Dolphins, B) Synchronized Screams of spotted dolphins, C) Frequency-modulated Whistles/Buzzes of bottlenose dolphins, D) Synchronized Brays/Buzz of bottlenose dolphins, and E) Synchronized Buzz of bottlenose dolphins. 
A) Zoom in of the details of the Bray/Buzz - Bottlenose Dolphins

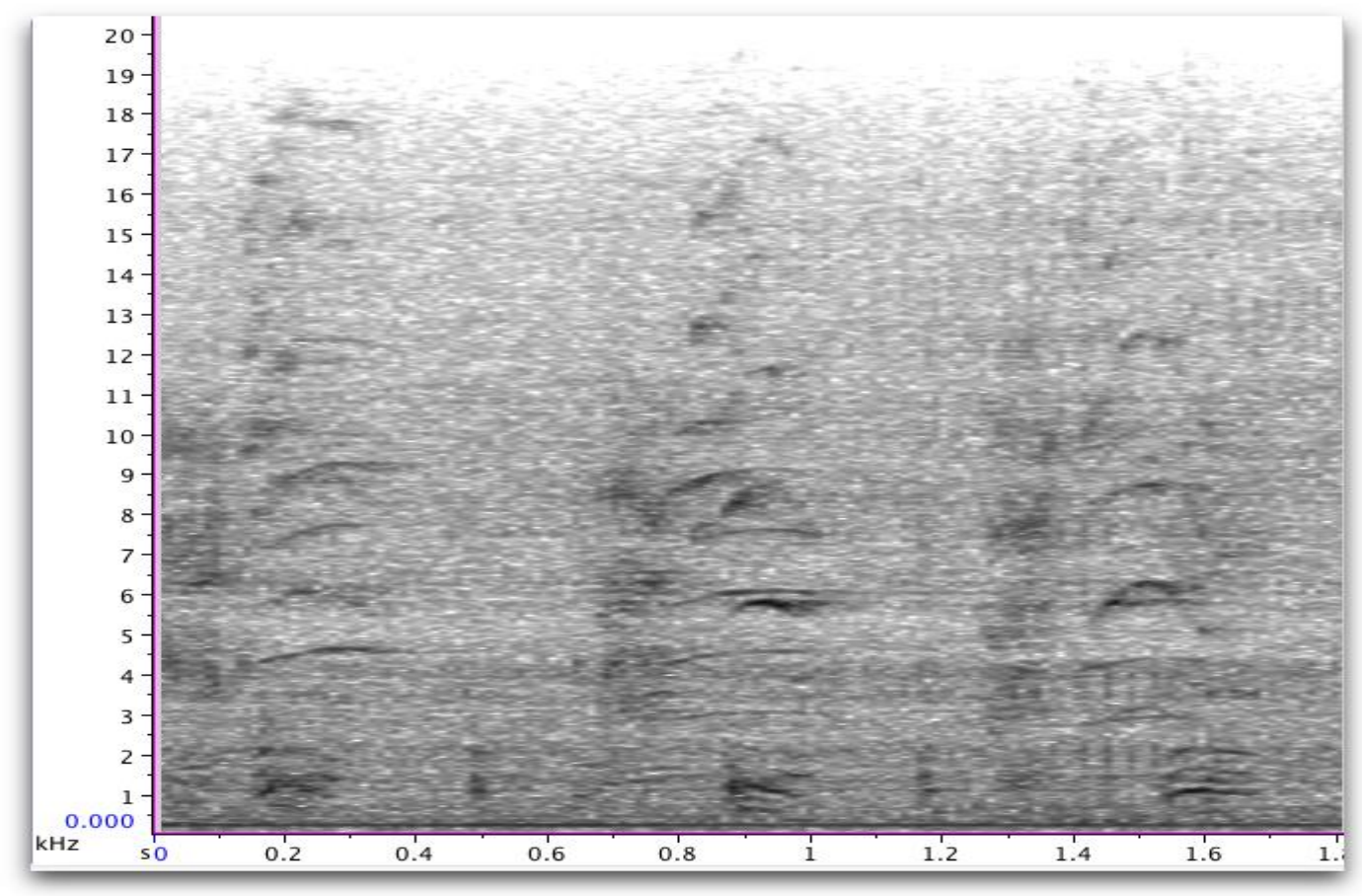

B) Zoom out of Synchronized Buzzes showing rhythmic aspects - Bottlenose Dolphins

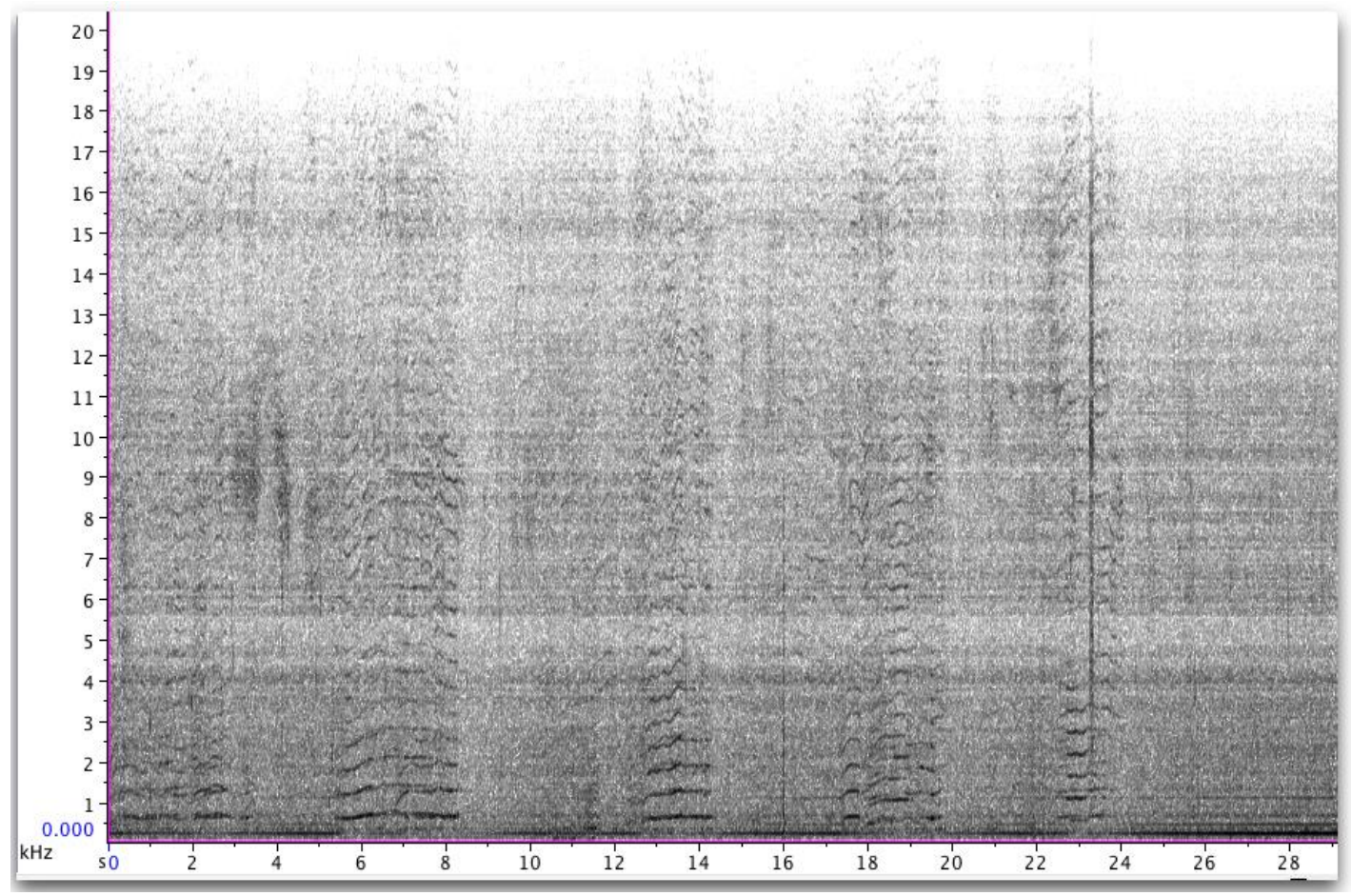

Figure 4. Details of some rhythmic vocalizations including A) Zoom in of the details of the Bray/Buzz of bottlenose dolphins, and B) Zoom out of Synchronized Buzzes showing rhythmic aspects of bottlenose dolphins 
Table 2

Measurements of Five Types of Synchronous Vocalizations in Two Species of Delphinids

\begin{tabular}{|c|c|c|c|c|c|c|}
\hline $\begin{array}{c}\text { Type of } \\
\text { Vocalization }\end{array}$ & $\begin{array}{l}\text { Vocalization } \\
\text { Duration } \\
\text { Mean /SD } \\
\text { (seconds) }\end{array}$ & $\begin{array}{c}\text { Intersignal } \\
\text { Interval (ISI) } \\
\text { Mean/SD } \\
\text { (seconds) }\end{array}$ & $\begin{array}{c}\text { Frequency } \\
\text { Range } \\
(\mathrm{kHz})\end{array}$ & $\begin{array}{l}\text { VOC/ISI } \\
\text { Ratio }\end{array}$ & Species & $\begin{array}{c}\text { Behavioral } \\
\text { Context }\end{array}$ \\
\hline $\begin{array}{c}\text { Synchronized } \\
\text { Squawks } \\
\mathrm{N}=46\end{array}$ & $0.18 / 0.10$ & $0.36 / 0.33$ & N/A & 0.51 & Ad Sp Only & $\begin{array}{c}\text { Intraspecific } \\
\text { Aggression }\end{array}$ \\
\hline $\begin{array}{l}\text { Synchronized } \\
\text { Squawks } \\
\mathrm{N}=63\end{array}$ & $0.50 / 0.33$ & $0.64 / 0.50$ & N/A & 0.78 & Juv Sp Only & $\begin{array}{c}\text { Intraspecific } \\
\text { Aggression }\end{array}$ \\
\hline $\begin{array}{l}\text { Synchronized } \\
\text { Squawks } \\
\mathrm{N}=70\end{array}$ & $0.52 / 0.31$ & $0.60 / 0.53$ & N/A & 0.87 & $\mathrm{Ad} \mathrm{Sp/Bn}$ & $\begin{array}{c}\text { Interspecific } \\
\text { Aggression }\end{array}$ \\
\hline $\begin{array}{l}\text { Maximum } \\
\text { Synchrony }\end{array}$ & $\begin{array}{c}\text { Pre/post } \\
0.54 / 0.32\end{array}$ & $\begin{array}{c}\text { Pre/post } \\
0.63 / 0.57\end{array}$ & N/A & $\begin{array}{c}\text { Pre/post } \\
0.86\end{array}$ & Ad $\mathrm{Sp} / \mathrm{Bn}$ & $\begin{array}{c}\text { Interspecific } \\
\text { Aggression }\end{array}$ \\
\hline $\begin{array}{l}\text { Measurements } \\
\quad \mathrm{N}=70\end{array}$ & $\begin{array}{c}\text { Max synch } \\
0.42 / 0.04\end{array}$ & $\begin{array}{c}\text { Max synch } \\
0.28 / 0.02\end{array}$ & & $\begin{array}{c}\text { Max synch } \\
1.48\end{array}$ & & \\
\hline $\begin{array}{l}\text { Synchronized } \\
\text { Screams } \\
\mathrm{N}=24\end{array}$ & $1.14 / .44$ & $0.40 / 0.22$ & $5.373-6.893 \mathrm{kHz}$ & 2.87 & Ad Sp Only & $\begin{array}{c}\text { Intra \& } \\
\text { Interspecific } \\
\text { Aggression }\end{array}$ \\
\hline $\begin{array}{c}\text { Synchronized } \\
\text { Whistle/Buzz } \\
\text { Bout } \\
\mathrm{N}=9\end{array}$ & $\begin{array}{c}\text { Wh } 1.08 / 0.12 \\
\text { Buzz 0.75/0.15 } \\
\text { Bout } 2.05 / 0.27\end{array}$ & $\begin{array}{c}\text { Wh/Buzz } \\
0.22 / 0.07 \\
\text { Bout } 0.84 / 0.15\end{array}$ & $\begin{array}{c}\text { Wh } 4.291-9.343 \mathrm{kHz} \\
\text { Avg change } \\
5.052 \mathrm{kHz}\end{array}$ & 2.44 & Bn Only & $\begin{array}{l}\text { Intraspecific } \\
\text { Aggression } \\
\text { \& Courtship }\end{array}$ \\
\hline $\begin{array}{c}\text { Synchronized } \\
\text { Bray/Buzz Bout } \\
\mathrm{N}=6\end{array}$ & $\begin{array}{l}\text { Bray 1.42/0.29 } \\
\text { Buzz 0.50/0.05 } \\
\text { Bout 1.92/0.31 }\end{array}$ & $\begin{array}{c}\text { N/A } \\
\text { Bout } 0.76 / 0.20\end{array}$ & N/A & 2.52 & Bn Only & $\begin{array}{l}\text { Intraspecific } \\
\text { Aggression } \\
\text { \& Courtship }\end{array}$ \\
\hline $\begin{array}{l}\text { Synchronized } \\
\text { Buzz Bouts } \\
\mathrm{N}=5\end{array}$ & $2.90 / 0.67$ & $3.02 / 0.88$ & N/A & 0.96 & Bn Only & $\begin{array}{l}\text { Intraspecific } \\
\text { Aggression } \\
\text { \& Courtship }\end{array}$ \\
\hline
\end{tabular}

\section{Results}

\section{Atlantic Spotted Dolphin Synchronized Vocalizations}

1. Synchronized Squawks - Intraspecific Spotted Dolphins. Squawks were about one-half the duration of the ISI after a squawk (ratio of SSQ to the ISI was 0.51:1). The mean duration for adult spotted dolphins synchronized squawks was $0.18 \mathrm{~s}(S D 0.10)$ and the mean duration for the ISI was $0.36 \mathrm{~s}$ (SD 0.33). Juvenile squawks were shorter in duration than the ISI following a squawk (ratio of SSQ to ISI was $0.78: 1$ ). The mean duration for juvenile spotted dolphin synchronized squawks was 0.50 (SD 0.33 ) and the mean duration for ISI was $0.64 \mathrm{~s}(S D 0.50)$.

2. Synchronized Scream Bouts - Intra and Interspecific Aggression. Screams were almost three times as long as the ISI between scream bouts (ratio of SCR to ISI was 2.87:1). The mean duration of a scream bout in adult male spotted dolphins was $1.14 \mathrm{~s}(S D 0.44)$ and the mean duration for the ISI was $0.40 \mathrm{~s}$ ( $S D$ 0.22). Screams were modulated between $5.373 \mathrm{kHz}$ and $6.893 \mathrm{kHz}$. 
3. Synchronized Squawks - Interspecific Aggression. Squawks were shorter than the ISI that followed a squawk (ratio of SQ to ISI duration was 0.87:1). The mean duration for adult spotted dolphin synchronized squawks during interspecies aggression was $0.52 \mathrm{~s}(S D 0.31)$ and the mean duration for the ISI was $0.60 \mathrm{~s}$ ( $S D$ 0.53). This sequence was also broken down by pre/post synchrony and maximum synchrony. Before and after maximum physical synchrony occurred squawks remained a bit shorter than the ISI that followed a squawk (ratio of SSQ to ISI was 0.86:1). During pre/post synchrony the mean duration of a squawk was $0.54 \mathrm{~s} \mathrm{(SD} \mathrm{0.32)} \mathrm{and} \mathrm{the} \mathrm{mean} \mathrm{duration} \mathrm{of} \mathrm{the} \mathrm{ISI} \mathrm{was} 0.63 \mathrm{~s}(S D$ 0.57). During maximum postural and acoustic synchrony squawks were one and one-half the duration of the ISI that followed the squawk (ratio of SQ to ISI was 1.48:1), the mean duration of a squawk was $0.42 \mathrm{~s} \mathrm{(SD} \mathrm{0.04),}$ and the mean duration of the ISI was 0.28 (SD 0.02). The standard deviation of both the squawk and the ISI during maximum synchrony was also low (0.04/0.02) verifying the strong rhythmic aspect of the sequence during maximum physical synchrony.

\section{Bottlenose Dolphin Synchronized Vocalizations}

1. Whistle/Buzz Bouts. The mean duration of whistles was $1.08 \mathrm{~s}$ ( $S D$ 0.12). Frequencies of whistles ranged between $4.291 \mathrm{kHz}-9.343 \mathrm{kHz}$ with an average frequency change of $5.052 \mathrm{kHz}$. The mean duration of the interval between whistle and the buzz was $0.22 \mathrm{sec}(S D 0.07)$. The mean duration of the buzz was $0.75 \mathrm{~s}(S D$ 0.15). The mean duration of the whistle/buzz bout combined was $2.05 \mathrm{~s}(S D$ 0.27 ). The mean duration of the interval between whistle bouts was $0.84 \mathrm{sec}(S D 0.15)$. The whistle/buzz bout was two and one-half times the duration of the ISI following the bout (ratio of whistle/buzz bout to ISI was 2.44:1).

2. Bray/Buzz Bouts. The mean duration of a bray sequence was $1.42 \mathrm{~s}$ ( $S D$ 0.29). The mean duration of a buzz was 0.50 (SD 0.05). The mean duration of the Bray/buzz bout combined was $1.92 \mathrm{sec}$ $(S D$ 0.31). The mean duration of the ISI following the bray/buzz bout was $0.76 \mathrm{~s}$ (SD 0.20). The bray/buzz bout was two and one-half times the duration of the ISI following the bout (ratio of Bray/Buzz bout to ISI was 2.52:1).

3. Buzz Bouts. The mean duration of a buzz was $2.90 \mathrm{~s}$ (SD 0.67). The mean duration of the ISI interval was $3.02 \mathrm{~s}(S D$ 0.88). Buzzes and their ISI were near parity (ratio between the buzz and the following ISI was 0.96:1).

\section{Discussion}

This study focused on describing the presence of synchronous vocal events during underwater behaviors. Adult Atlantic spotted dolphins show tight rhythmic qualities in their synchronized screams and squawks as compared to juvenile spotted dolphin examples. In both adult and juvenile spotted dolphins, squawks were typically $0.5 \mathrm{~s}$ or less, with slightly longer ISIs. In one sequence where measurements were taken when acoustic rhythm was at a maximum (spacing between vocalizations had the smallest SD and when physical synchrony was tight) the ratio of the duration of squawk to ISI was 1.48:1, as compared to pre and post maximum synchrony ratio of $0.86: 1$. In addition, during maximum coordination the SD of both the squawk duration and the ISI duration was very low (0.04/0.02) further showing the consistent quality of spacing and rhythm. Synchronized screams were also consistent in spacing but had a longer duration of screams relative to the ISI $(2.87: 1)$.

Bottlenose dolphins used a variety of synchronized vocalizations during an intraspecific aggressive context. Bottlenose dolphins used three different types of bouts, one with whistles/buzzes, one with bray/buzzes, and one with only buzzes during these rhythmic vocal sequences. Bottlenose dolphins that synchronized vocalization bouts (whistle/buzz, brays/buzz, and buzz) showed rhythmic qualities. During Whistles/Buzz and Bray/Buzz Bouts bottlenose dolphins combine either a multiple whistles, or 
multiple brays, with a buzz during rhythmic sequences. In both examples, the combined vocalization (e.g., whistle plus buzz, or brays plus buzz) duration was over two times the duration of the ISI between bouts (2.44/2.52). Therefore, when dolphins used a whistle/buzz or a bray/buzz, the ratio between the vocalization bout and the interval between was similar in duration. Synchronized buzzing was also rhythmic with close to parity ratio between the sound and the ISI $(0.96: 1)$.

Although both whistles and brays have been reported in the literature, the rhythmic aspect has not been reported in detail. In Scotland, Janik (2000) reported the context of Brays in feeding behavior, based on surface observations of fast swimming. However the brays observed underwater in the Bahamas occurred during social behavior, specifically male fighting and during the pursuit of females. The occurrence of multiple bray vocalization "type" bouts, in combinations with many different signals, by bottlenose dolphins in Portugal has been reported during surface observations of both feeding and social interaction (dos Santos et al., 1995). In all 3 study sites, the frequency of bray occurrence seems rare and it may also be that this sound is used in multiple contexts in the wild.

Young Atlantic spotted males (ages 4-8), during the development of alliance behavior, show partial synchronization of both swimming behavior and squawks during mock fights (Herzing, unpublished data) but their vocalizations bouts are rarely fully synchronized or rhythmic to meet the criteria of vocal synchrony. Learning the appropriate rhythmic spacing of a signal, and learning to coordinate such signals as a group, may occur during these developmental years. This suggests that young dolphins may need to learn and practice synchronization skills as they practice other skills during developmental periods (Bender, Herzing, \& Bjorklund, 2009). Small delphinids are known for vocal learning that includes mimicry during natural interactions in the wild (Sayigh, Quick, Hastie, \& Tyack, 2013) and spontaneous mimicry during exposure to mechanical signals like sonar (DeRuiter et al., 2013).

In other taxa synchrony is known to occur in the context of multi-male displays of sexual advertisement to attract female conspecifics. Male cooperation in these displays raises the question of why a male should cooperate in attracting a female to a group with whom he might have to share her. Detailed studies of synchronous display have generated both formal treatments of mechanisms of entrainment (Sismondo, 1990) and a number of models for the evolution of multi-male synchrony. Greenfield, Tourtellot, and Snedden (1997) suggested that the adaptive significance of chorusing is used by competing males to jam each other's signals. In the Bahamas, the use of synchronous and overlapping brays and buzzes occurred in the presence of interacting dyads of bottlenose dolphins and potentially support this competitive theory, although female pursuit was also observed suggesting that perhaps these vocalizations serve two simultaneous purposes. However, synchronous squawks and screams occurred only when alliances of 3-8 Atlantic male spotted dolphins were present and coordinating against a foe, showing support for a previous hypotheses by Greenfield (1994) who suggested that male signalers chorus to establish a group-level condition in which their avoidance and confrontation of enemies is enhanced. It may be that different types of vocalizations serve these different functions (squawks/screams to coordinate and bray/buzzes to jam, etc.). All overlapping vocalizations displayed rhythmic temporal intervals between bouts of sounds indicating that they are rhythmic in nature, at least in adult dolphin behavior.

Synchronous calling during true cooperative synchronous behavior is important because simultaneous calling can serve as an amplitude summation of a signal for a group as well as signal coordinated effort. The quality, or level of exact synchrony itself, provides a further measure of male cooperation as well as vocal skill. During behavioral synchrony a male group whose calling extends the reach of its signal by decibel summation would be likely to either deter additional challengers, attract other coalitions of males (dolphins have been observed to form second and third level alliances - Connor et al., 2006; Elliser \& Herzing 2014), or potentially attract a greater number of females. Smolker and Pepper (1999) and later Watwood, Tyack, and Wells (2004) established call "type" convergence in male bottlenose dolphin whistles (Tursiops sp.) at two separate field sites. It is likely that call convergence reflects a group identifier that is distinct and may also reflect the degree of social bonds between individuals. 
Cusick and Herzing (2014) recently described detailed video analysis of the dynamic process of physical coordination during interspecies interactions between these two species of dolphin in the Bahamas, showing that synchronized physical postures were the deciding factor for the smaller species (spotted dolphins) gaining an upper hand with the physically larger dominant species (bottlenose dolphins). Together the visual and acoustic modalities may form a more powerful signal than one modality alone. It is not known if one species modifies its signal (visual or acoustic) when dealing with an interspecific event vs. an intraspecific event. The importance of behavioral coordination between individuals using acoustic rhythmic signals, which lead to the coordination of movement, has also been discussed by other researchers (Di Paolo, 2000). Synchrony and rhythm have evolved in a variety of taxa and potentially for a variety of reasons. Pulse-born behavioral synchrony is fairly unique in humans with the exception of pulse-based rhythmicity found in music, dance, and poetry (Merker, Madison, \& Eckerdal, 2009). Others have described the roots of neuronal synchrony in the brain (e.g., Singer, 1999) suggesting that many taxa may have the infrastructure to evolve synchrony as a valuable mechanism. Both the use of synchrony, and the mechanisms involved, should be examined further to fully understand the function of synchrony. The development of synchrony, and the modification of signals within and between species, is a fruitful area of further investigation to understand the long-term process of synchrony in evolution.

\section{Acknowledgments}

This research was supported by foundations, donors and members of the Wild Dolphin Project. Thanks to the crew and staff of WDP. All work was undertaken under a Bahamas Department of Fisheries Research Permit.

\section{References}

Altmann, J. (1974). Observational study of behavior: Sampling methods. Behaviour, 49, 227-267.

Baker-Médard, M. S., Baker, M. C., \& Logue, D. M. (2013). Chorus song of the Indri (Indri indri: Primates, Lemuridae): Group differences and analysis of within-group vocal interactions. International Journal of Comparative Psychology, 26, 241-255.

Backwell, P., Jennions, M., \& Passmore, N. (1998). Synchronized courtship in fiddler crabs. Nature, 391, 31-32.

Bender, C. E., Herzing, D. L., \& Bjorklund, D. F. (2009). Evidence of teaching in Atlantic spotted dolphins (Stenella frontalis) by mother dolphins foraging in the presence of their calves. Animal Cognition, 12, 43-53.

Brownlee, S. M., \& Norris, K. S. (1994). The acoustic domain. In K. S. Norris, B. Würsig, R. S. Wells, \& M. Würsig (Eds.), The Hawaiian spinner dolphin (pp. 161-185). Berkeley, CA: University of California Press.

Buck, J. (1988). Synchronous rhythmic flashing in fireflies. Quarterly Review Biology, 63, 265-289.

Boesch, C. (1991). Symbolic communication in wild chimpanzees? Human Evolution, 6, 81-90.

Caldwell, M. C., Caldwell, D. K., \& Tyack, P. L. (1990). Review of the signature whistle hypothesis for the Atlantic bottlenose dolphin. In S. Leatherwood \& R. R. Reeves (Eds.) The bottlenose dolphin (pp. 199-233). San Diego: Academic Press.

Connor, R. C., \& Smolker, R. A. (1996). 'Pop" goes the dolphins: A vocalization male bottlenose dolphins produce during consortships. Behaviour, 133, 643-662.

Connor, R. Smolker, R., \& Bejder, L. (2006). Synchrony, social behaviour and alliance affiliation in Indian Ocean bottlenose dolphins, Tursiops aduncus. Animal Behavior, 72, 1371-1378.

Connor, R. C., Smolker, R. A., \& Richards, A. F. (1992). Two levels of alliance formation among male bottlenose dolphins (Tursiops sp.). Proceeding of the National Academy of Science USA, 89, 987-990.

Coscia, E. M., Phillips, D. P., \& Fentress, J. C. (1991). Spectral analysis of neonatal wolf, Canis lupus vocalizations. Bioacoustics, 3, 275-293.

Cusick, J. A., \& Herzing, D. L. (2014). The dynamic of aggression: How individual and group factors affect the long-term interspecific aggression between two sympatric species of dolphin. Ethology, 120, 287-303.

de Waal, F. B. M. (1988). The communicative repertoire of captive bonobos (Pan paniscus) compared to that of chimpanzees. Behavior, 106, 183-251.

Di Paolo, E. A. (2000). Behavioral coordination, structural congruence and entrainment in a simulation of 
acoustically coupled agents. Adaptive Behavior, 8, 27-48.

DeRuiter, S. L., Boyd, I. L., Claridge, D. E., Clark, C. W., Gagnon, C., Southall, B. L., \& Tyack, P. L. (2013). Delphinid whistle production and call matching during playback of simulated military sonar. Marine Mammal Science, 29, E46-E59.

dos Santos, M. E., Caporin, G., Moreira, H. O., Ferreira, A. J., \& Coelho, J. L. B. (1990). Acoustic behavior in a local population of bottlenose dolphins. In J. A. Thomas \& R. A. Kastelein (Eds.), Sensory abilities of cetaceans (pp. 585-598). New York: Plenum Press.

dos Santos, M. E., Ferreira, A. J., \& Harzen, S. (1995). Rhythmic sound sequences emitted by aroused bottlenose dolphins in the Sado estuary, Portugal. In J. A. Thomas, R. A. Kastelein, \& P. E. Nachtigall (Eds.), Sensory abilities of cetaceans (pp. 325-334). De Woerden, The Netherlands: Spil Publisher.

Elliser, C. R., \& Herzing, D. L. (2012). Community structure and cluster definition of Atlantic spotted dolphins, Stenella frontalis, in the Bahamas. Marine Mammal Science, 28, E486-E502.

Elliser, C. R., \& Herzing, D. L. (2014). Long-term social structure of a resident community of Atlantic spotted dolphins, Stenella frontalis, in the Bahamas 1991-2002. Marine Mammal Science, 30, 308-328.

Green, M. L., Herzing, D. L., \& Baldwin, J. D. (2011). Reproductive success of male Atlantic spotted dolphins (Stenella frontalis) revealed by noninvasive genetic analysis of paternity. Canadian Journal of Zoology, 89, 239-253.

Greenfield, M. D. (1994). Synchronous and alternating choruses in insects and anurans: Common mechanisms and diverse functions. American Zoologist, 34, 605-615.

Greenfield, M., \& Roizen, I. (1993). Katydid synchronous chorusing is an evolutionarily stable outcome of female choice. Nature, 364, 618-620.

Greenfield, M. D., \& Shaw, K. C. (1983). Adaptive significance of chorusing with special reference to the Orthoptera. In D. T. Gwynne \& G. K. Morris (Eds.), Orthopteran mating systems: Sexual competition in a diverse group of insects (pp. 1-27). Boulder, CO: Westview Press.

Greenfield, M. D., Tourtellot, M. K., \& Snedden, W. A. (1997). Precedence effects and the evolution of chorusing. Proceedings of the Royal Society of London. Series B: Biological Sciences, 264(1386), 1355-1361.

Haimoff, E. H. (1986). Convergence in the duetting of monogamous Old World primates. Journal of Human Evolution, 15, 51-59.

Hastie, G. D., Wilson, B., Tufft, L. H., \& Thompson, P. M. (2003). Bottlenose dolphins increase breathing synchrony in response to boat traffic. Marine Mammal Science, 19, 74-84.

Heimlich-Boran, J. R. (1988). Behavioral ecology of killer whales (Orcinus orca) in the Pacific Northwest. Canadian Journal of Zoology, 66, 565-578.

Hershey, J., \& Movellan, J. (1999). Audio-vision: Using audio-visual synchrony to locate sounds. In Advances in Neural Information Processing Systems, 12, 813-819.

Herzing, D. L. (1996). Vocalizations and associated underwater behavior of free-ranging Atlantic spotted dolphins, Stenella frontalis and bottlenose dolphins, Tursiops truncatus. Aquatic Mammals, 22, 61-79.

Herzing, D. L. (1997). The life history of free-ranging Atlantic spotted dolphins (Stenella frontalis) age classes, color phases, and female reproduction. Marine Mammal Science, 13, 576-595.

Herzing, D. L. (2000) Acoustics and social behavior of wild dolphins: Implications for a sound society. In W.W. L. $\mathrm{Au}, \mathrm{A}$. N. Popper, \& R. R. Fay (Eds.), Hearing in whales, Springer-Verlag handbook of auditory research (pp. 225-272). Springer-Verlag: New York.

Herzing, D. L. (2004). Social and nonsocial uses of echolocation in free-ranging Stenella frontalis and Tursiops truncatus. In J. A. Thomas, C. F. Moss, \& M. Vater (Eds.), Advances in the study of echolocation in bats and dolphins (pp. 404-410). University of Chicago Press: Chicago and London.

Herzing, D. L., \& Johnson, C. M. (1997). Interspecific interactions between Atlantic Spotted dolphins (Stenella frontalis) and bottlenose dolphins (Tursiops truncatus) in the Bahamas, 1985-1995. Aquatic Mammals, 23, $85-99$.

Janik, V. M. (2000). Food-related bray calls in wild bottlenose dolphins (Tursiops truncatus). Proceedings of the Royal Society of London. Series B: Biological Sciences, 267(1446), 923-927.

Janik, V. M., Simard, P., Sayigh, L. S., Mann, D., \& Frankel, A. (2011). Chorussing in delphinids. The Journal of the Acoustical Society of America, 130, 2322.

Janik, V. M., \& Slater, P. J. B. (1997). Vocal learning in mammals. Advances in the Study of Behavior, 26, 59-99.

Janik, V. M., \& Slater, P. J. B. (2000). The different roles of social learning in vocal communication. Animal Behavior, 60, 1-11.

Klump, G. M., \& Gerhardt, H. C. (1992). Mechanisms and function of call-timing in male-male interactions in frogs. In P. K. McGregor (Ed.), Playback and studies of animal communication (pp. 153-174). New York: Plenum 
Press.

Lammers, M. O., Au, W. W. L., \& Herzing, D. L. (2003). The broadband social acoustic signaling behavior of spinner and spotted dolphins. The Journal of the Acoustical. Society of America, 114, 1629-1639.

Maier, V. (1982). Acoustic communication in the guinea fowl (Numida meleagris): Structure and use of vocalizations, and the principles of message coding. Zeitschrift Für Tierpsychologie, 59, 29-83.

McCowan, B., \& Reiss, D. (1995). Quantitative comparison of whistle repertoires from captive adult bottlenose dolphins (Delphinidae, Tursiops truncatus): A re-evaluation of the signature whistle hypothesis. Ethology, 100, 194-209.

Mann, J., \& Smuts, B. (1999). Behavioral development in wild bottlenose dolphin newborns (Tursiops sp.). Behaviour, 136, 529-566.

Marler, P., \& Mundinger, P. (1971). Vocal learning in birds. In H. Moltz (Ed.), The ontogeny of vertebrate behavior (pp. 389-450). New York: Academic Press.

Merker, B. H., Madison, G. S., \& Eckerdal, P. (2009). On the role and origin of isochrony in human rhythmic entrainment. Cortex, 45, 4-17.

Nottebohm, F. (1976). Vocal tract and brain: A search for evolutionary bottlenecks. Annals of the New York Academy of Sciences, 280, 643-649.

Nityananda, V., \& Balakrishnan, R. (2008). Leaders and followers in katydid choruses in the field: Call intensity, spacing and consistency. Animal Behaviour, 76, 723-735.

Otte, D. (1977). Communication in Orthoptera. In T. A. Sebeok (Ed.), How animals communicate (pp. 334-361). Bloomington, IN: Indiana University Press.

Overstrom, N. A. (1983). Association between burst-pulse sounds and aggressive behavior in captive Atlantic bottlenose dolphins (Tursiops truncatus). Zoo Biology, 2, 93-103.

Perelberg, A., \& Schuster, R. (2008). Coordinated breathing in bottlenose dolphins (Tursiops truncatus) as cooperation: Integrating proximate and ultimate explanations. Journal of Comparative Psychology, 122, 109.

Perrin, W. F. (1970). Color pattern of the eastern Pacific spotted porpoise Stenella graffmani Lönnberg (Cetacea, Delphinidae). Zoologica, 54, 135-149.

Pryor, K., \& Kang-Shallenberger, I. (1991). Social structure in spotted dolphins (Stenella attenuata) in the tuna purse seine fishery in the Eastern Tropical Pacific. In K. Pryor \& K. S. Norris (Eds.), Dolphin societies: Discoveries and puzzles (pp. 161-196). Berkeley: University of California Press.

Robinson, J. G. (1981). Vocal regulation of inter-and intragroup spacing during boundary encounters in the titi monkey, Callicebus moloch. Primates, 22, 161-172.

Sakai, M., Morisaka, T., Kogi, K., Hishii T., \& Kohshima, S. (2009). Fine-scale analysis of synchronous breathing in wild Indo-Pacific bottlenose dolphins (Tursiops aduncus). Behavioural Processes, 83, 48-53.

Sayigh, L., Quick, N., Hastie, G., \& Tyack, P. (2013). Repeated call types in short-finned pilot whales, Globicephala macrorhynchus. Marine Mammal Science, 29, 312-324.

Senigaglia, V., \& Whitehead, H. (2012). Synchronous breathing by pilot whales. Marine Mammal Science, 28, 213219.

Singer, W. (1999). Neuronal synchrony: A versatile code for the definition of relations? Neuron, 24, 49-65.

Sismondo, E. (1990). Synchronous, alternating, and phase-locked stridulation by a tropical katydid. Science, 249 (4964), 55-58.

Smolker, R., \& Pepper, J. W. (1999). Whistle convergence among allied male bottlenose dolphins (Delphinidae, Tursiops sp.). Ethology, 105, 595-617.

Sjare, B. L., \& Smith, T. G. (1986). The vocal repertoire of white whales, Delphinapterus leucas, summering in Cunningham Inlet, Northwest Territories. Canadian Journal of Zoology, 64, 407-415.

Tyack, P. (1993). Animal language research needs a broader comparative and evolutionary framework. In H. L. Roitblat, L. M. Herman, \& P. E. Nachtigall (Eds.). Language and communication - comparative perspectives (pp. 1115-1138). Hillsdale, NJ: Lawrence Erlbaum Associates.

Watwood, S. L., Tyack, P. L., \& Wells, R. S. (2004). Whistle sharing in paired male bottlenose dolphins, Tursiops truncatus, Behavioral Ecology and Sociobiology, 55, 531-543.

Wells, K. D. (1977). The social behavior of anuran amphibians. Animal Behaviour, 25, 666-693.

Whitehead, H. (1996). Babysitting, dive synchrony, and indications of alloparental care in sperm whales. Behavioral Ecology and Sociobiology, 38, 237-244.

Zelick, R. D., \& Narins, P. M. (1983). Intensity discrimination and the precision of call timing in two species of neotropical treefrogs. Journal of Comparative Physiology A: Neuroethology, Sensory, Neural, and Behavioral Physiology, 153, 403-412. 